\title{
Mutación en el gen EDA1, Ala349Thr en paciente con displasia ectodérmica hipohidrótica ligada a X
}

\author{
JULIO C. SALAS-ALANIS ${ }^{1,}$, RODRIGO CEPEDA-VALDÉS ${ }^{3}$, \\ ADRIANA GONZÁLEZ-SANTOS², MARIO AMAYA-GUERRA², \\ MAZEN KURBAN ${ }^{3}$, ANGELA M. CHRISTIANO ${ }^{3}$

\section{Mutation in the ED1, Ala349Thr in a patient with X-linked hypohidrotic ectodermal dysplasia}

Hypohidrotic ectodermal dysplasia (HED) is a very rare disease characterized by the absence of eccrine glands, dry skin, scanty hair, and dental abnormalities. It is caused by mutations within the ED1 gene, which encodes a protein, ectodysplasin-A (EDA). Clinical characteristic are frontal bossing, saddle nose, pointed chin, a prominent supraorbital ridge with periorbital hyperpigmentation, and anodontia. Those affected show great intolerance to heat. We report the first Mexican 2-year-old boy with an Ala349Thr missense mutation from Tamaulipas, México.

(Rev Med Chile 2011; 139: 1601-1604).

Key words: Ectodermal dysplasia, hypohidrotic; Ectodysplasias; Mutation, missense.

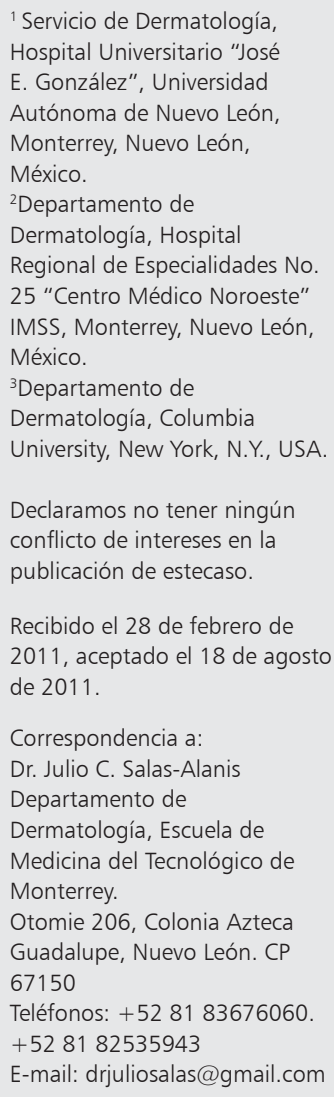

L a displasia ectodérmica comprende un grupo heterogéneo de anormalidades caracterizadas por alteraciones que involucran al menos 2 o más tejidos derivados de la capa embrionaria ectodérmica, como piel, dientes, pelo, uñas, glándulas sudoríparas y glándulas sebáceas.

La enfermedad inicialmente fue descrita por Thurman en 1848, posteriormente en 1875 Charles Darwin describe el patrón de herencia de la enfermedad, recesiva ligada al cromosoma X. En 1913, Christ la catalogó propiamente como un defecto congénito del ectodermo, siendo retomada en 1921 por Siemens, quien reafirmó el vínculo del padecimiento con el cromosoma $\mathrm{X}^{1-2}$. Aunque se han descrito alrededor de 170 tipos de displasias ectodérmicas, solamente 30 han sido genéticamente codificadas y definidas ${ }^{4,5,6}$. Dentro de este amplio rango de displasias congénitas, difusas y no progresivas, la más común es la displasia ectodérmica hipohidrótica $(\mathrm{DEH})$, recesiva ligada al cromosoma X, también conocido como síndrome Christ-Siemens-Touraine ${ }^{7}$. Los pacientes con DEH comúnmente presentan hipertermia debido a la disminución de glándulas ecrinas, hipodontia y dientes cónicos, dando como resultado dificultad para comer. Se presenta un caso de un niño con displasia ectodérmica hipohidrótica, y se hace la revisión del tema.

\section{Caso clínico}

Paciente masculino de 2 años de edad, originario de Tamaulipas, México, evaluado por xerosis generalizada, así como fiebre de origen incierto. Producto del segundo embarazo de una pareja sin antecedentes aparentes de consanguineidad, se caracteriza por presentar intolerancia al calor y ausencia de la sudoración desde el nacimiento. No refierían antecedentes heredofamiliares de importancia. En la exploración física destacaba la frente 

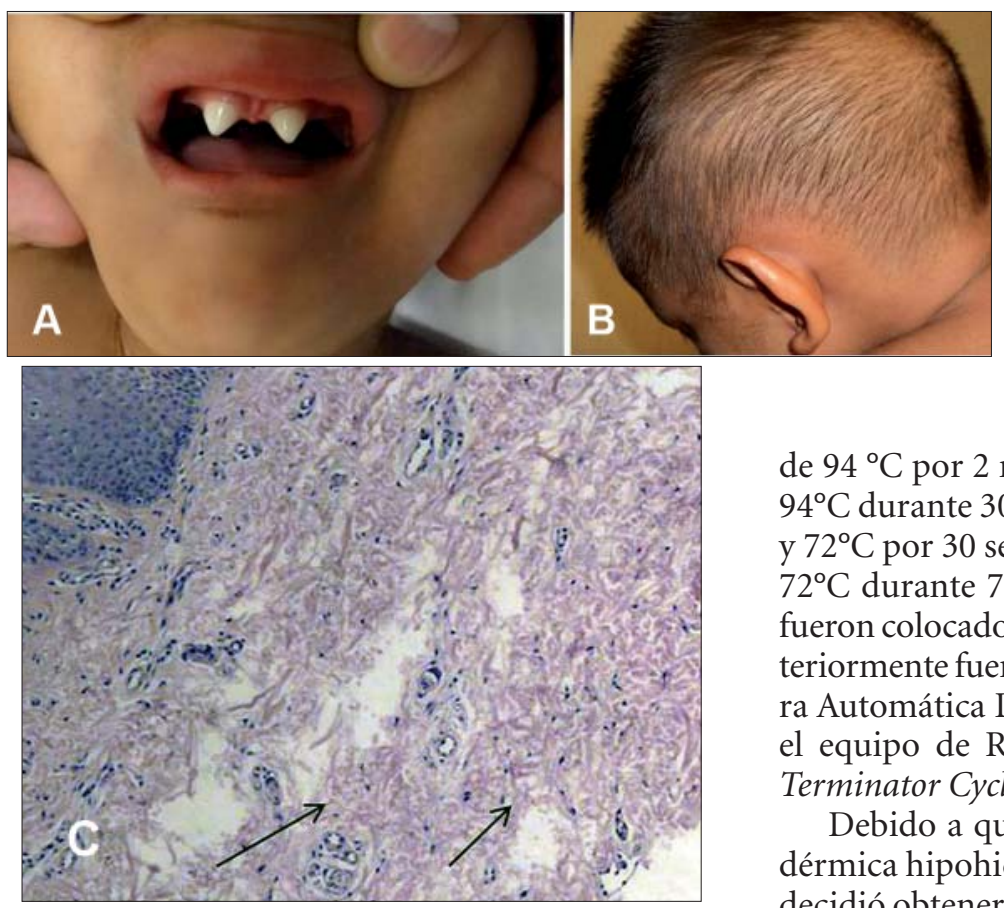

prominente, hipoplasia del puente nasal, dos incisivos únicos en forma de cono, pigmentación periorbitaria, pelo escaso, fino, disperso y frágil así como cejas y pestañas (Figura 1). El paciente presentaba una dermatosis diseminada a cabeza, tronco y principalmente en extremidades superiores e inferiores, constituida por pápulas puntiformes eritematosas, con eritema difuso en una piel xerótica.

La biopsia de piel de la palma de la mano izquierda demostró la ausencia parcial de las glándulas sudoríparas y sebáceas (Figura 1c). Después de obtener el consentimiento informado, obtuvimos sangre periférica para realizar el estudio de cariotipo reportándose normal y a la vez, obtuvimos sangre no coagulada en tubos de EDTA (ácido etilendiaminotetraacético) de todos los miembros de la familia siguiendo los Principios de la Declaración de Helsinki. Se extrajo ADN de las muestras sanguíneas utilizando el equipo PUREGENE $^{R}$ (Systema Gentra). Para el estudio de las mutaciones todos los exones así como las secuencias de los uniones de los intrones-exones fueron amplificados por medio de PCR (reacción en cadena de la polimerasa) del gen EDA-A1 en condiciones reportadas previamente. Las condiciones para la amplificación de cada PCR fueron
Figura 1. a-b Características clínicas de paciente con displasia ectodérmica hipohidróticafrente prominente, hipoplasia del puente nasal, dos incisivos únicos en forma de cono, pigmentación peri-orbitaria, pelo escaso, fino, disperso y frágil. c) Biopsia de piel de paciente con ausencia parcial de los folículos de pelo, glándulas sebáceas y ecrinas. HyE.40x.

de $94{ }^{\circ} \mathrm{C}$ por 2 minutos, seguido por 35 ciclos de $94^{\circ} \mathrm{C}$ durante 30 segundos, $55^{\circ} \mathrm{C}$ por 30 segundos y $72^{\circ} \mathrm{C}$ por 30 segundos con una extensión final a $72^{\circ} \mathrm{C}$ durante 7 minutos. Los productos de PCR fueron colocados en un gel de agarosa al $1 \%$ y posteriormente fueron analizados por la Secuenciadora Automática Directa ABI Prism 310, utilizando el equipo de Reacción "ABI PRISM ${ }^{\circledR} B i g D y e^{\mathrm{TM}}$ Terminator Cycle Sequencing” (PE Biosystem) ${ }^{8}$.

Debido a que comúnmente la displasia ectodérmica hipohidrótica se encuentra ligada a $X$, se decidió obtener ADN genómico, logrando identificar la mutación sinsentido Ala349Thr en el gen EDA, se realiza la correlación clínico-patológica, concluyendo así con el diagnóstico de displasia ectodérmica hipohidrótica. (Figura 2).

\section{Discusión}

Aunque la DEH es la más común de las displa-

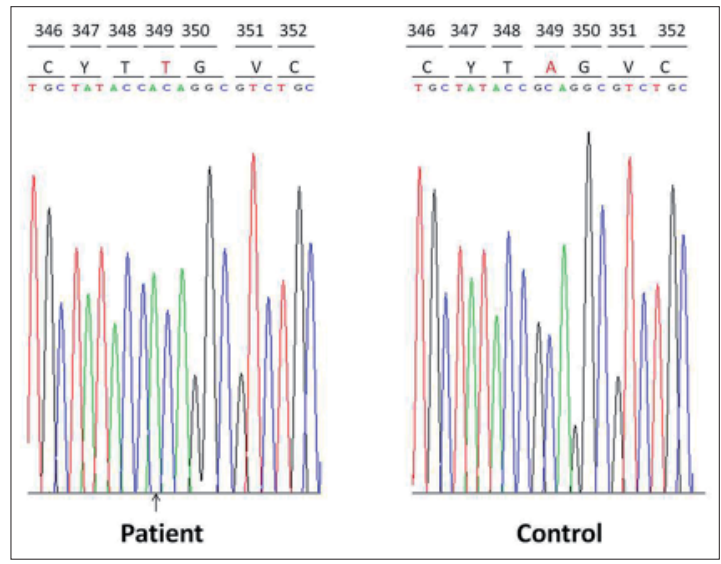

Figura 2. Comparación de la secuenciación del ADN del paciente y control, observe el cambio de una alanina por una treonina en la posición 349 de la lectura del marco genético. 
sias ectodérmicas, se considera un padecimiento relativamente raro. Esta genodermatosis es resultado del desarrollo embrionario anormal del ectodermo. La displasia ectodérmica hipohidrótica autosómica recesiva ligado al cromosoma $\mathrm{X}$ se origina a partir de la mutaciones en la proteína transmembrana ectodisplasina, localizada en el gen $\mathrm{EDA}^{5-10}$.

El patrón de herencia autosómico recesivo es causado por mutaciones en el gen DL que codifica para el receptor de la ectodisplasina y en el gen EDARADD, codificador de una proteína que interactúa con el receptor EDA. El gen NEMO codificada los receptores de la ectodisplasina A1 y de la proteínas transmembrana ectodisplasin A, el cual representa un ligando hidrosoluble necesario para activar las vías de señalización del factor nuclear kappa B (NF-KappaB) y quinasas c-Jun N-terminal (JNC/c-fos/c-jun). La proteína ectodisplasina A (EDA) pertenece a la familia del factor de necrosis tumoral (TNF) y juega un papel importante en la formación y regulación de las estructuras ectodérmicas ya que promueve la supervivencia, crecimiento y diferenciación de las células involucradas. La sustitución Ala349Thr se encuentra localizada en una región altamente conservada de la familia de receptores de TNF, mutaciones en la estructura de EDA afectan la interacción entre la EDA y sus receptores EDAR (receptor TNF que une al EDA-A1) y XEDAR (receptor TNF que une al EDA-A2).Estas proteínas se expresan en los queratinocitos de los folículos pilosos y glándulas sudoríparas, produciendo un defecto en el desarrollo que conlleva a la formación inadecuada o incompleta de folículos pilosos y glándulas sudoríparas, con alteraciones en la diferenciación de la queratinización folicular y el patrón de citoqueratinas (K13, K14,K19 Y K18). Debido a su etiopatogenia, la displasia ectodérmica hipohidrótica tiene diversas manifestaciones clínicas que pueden estar presentes o no, pero invariablemente una tríada clásica: hipohidrosis/ anhidrosis, hipotricosis y anodoncia ${ }^{5-12}$.

Al momento del nacimiento puede presentarse con una membrana espesa que recubre toda la piel, o con descamación de la piel, similar a la ictiosis congénita ${ }^{13}$. El cabello se visualiza muy fino, escaso, disperso y frágil, signo que pudiera ser desapercibido.

En el primer año la piel es xerótica, lisa, o áspera. El signo del "lienzo húmedo" está presente en algunos casos, así como dermatitis seborreica en la frente y mejillas debido a hipertrofia de las glándulas sebáceas, las cuales se encuentran recubiertas por tapones de queratina, dando el aspecto llamado "piel de lija"10.

Existe facies típica la cual es difícil de reconocer hasta la infancia, cuando se observa: frente olímpica, pirámide nasal hundida, labios evertidos, hiperpigmentación de la piel periorbitaria e implantación baja de orejas. Estos datos pueden estar presentes en diferentes grados de severidad.

Una característica particular de este síndrome está relacionada con los dientes cónicos, hipodoncia o anodoncia, así como retraso en la erupción de las piezas dentales. Puede presentarse onicodistrofia, xeroftalmia y/o conjuntivitis ${ }^{14-17}$.

La habilidad para sudar se encuentra sumamente comprometida debido a la falta de conductos sudoríparos en epidermis. Esto da lugar a una significativa intolerancia al calor, provocando en algunos casos convulsiones o retraso mental.

En general los exámenes de laboratorio no son necesarios para hacer el diagnóstico. Ante la sospecha clínica del síndrome, se sugiere realizar una biopsia de piel (zona hipotenar de la mano) para documentar la reducción o total ausencia de glándulas écrinas. Una prueba fehaciente y muy útil para demostrar la ausencia de sudoración es la prueba con nitrato de pilocarpina por vía subcutánea para estimular la sudoración. Otra alternativa para demostrar la anhidrosis es aplicar lugol y almidón en la región palmar. La prueba es positiva si el lugol, comúnmente amarillento, cambia su tonalidad a violácea. Es negativa si no se presenta ningún cambio. Las cuales no son necesarias ante los hallazgos en la biopsia de piel.

Las medidas preventivas y de higiene son las más importantes para los pacientes que padecen esta entidad. Es recomendable instruir al paciente acerca de la importancia de mantenerse en temperaturas frescas, si es posible, con aire acondicionado, para prevenir elevación de la temperatura corporal. Asimismo, es importante el consumo apropiado de líquidos para mantener una termorregulación adecuada. Disminuir actividad física en la mayor medida posible. Es imprescindible la visita con un experto para evaluación dental, así como enfatizar en la importancia de la higiene dental y bucal, siendo necesario el reemplazo o implante de las piezas dentales o inclusive prótesis dental total esto con el fin de facilitar la ingesta nutricional del paciente, y mejorar el aspecto 
estético. Con el objetivo de prevenir lesiones de la córnea, es necesario el uso de lágrimas artificiales, así como el uso de lubricante nasal para prevenir afecciones nasofaríngeas. El tratamiento integral, con terapéutica psicológica así como consulta genética son aspectos trascendentales en el tratamiento del paciente ${ }^{16-19}$.

Con la finalidad de analizar la recurrencia de las mutaciones en genodermatosis consideramos importante la búsqueda de la mutación Ala349Thr en pacientes mexicanos con DEH.

La DEH es una entidad en la cual el pronóstico de sobrevida es muy bueno. Si la entidad se reconoce desde temprana edad y es tratada adecuadamente mediante el apoyo con un equipo multidisciplinario de salud, la esperanza de vida no debería de verse afectada y la calidad de vida del paciente podría mejorar de manera exitosa.

\section{Referencias}

1. Solomon LM, Keuer EJ. The ectodermal dysplasias. Problems of classification and some newer syndromes. Arch Dermatol 1980; 116 (11): 1295-9.

2. Thurnam J. Two cases in which the skin, hair and teeth were very imperfectly developed. Med Chir Trans 1848; 31: 71-82.

3. Weech AA. Hereditary ectodermal dysplasia (congenital ectodermal defect) Am J Dis Child 1929; 37: 766-90.

4. Smith FJ, Jonkman MF, van Goor H, Coleman CM, Covello SP, Uitto J, et al. A mutation in human keratin K6b produces a phenocopy of the K17 disorder pachyonychia congenita type 2. Hum Mol Genet Jul 1998; 7 (7): 1143-8.

5. McLean WH, Rugg EL, Lunny DP, Morley SM, Lane EB, Swensson O, et al. Keratin 16 and keratin 17 mutations cause pachyonychia congenita. Nat Genet Mar 1995; 9 (3): 273-8.

6. Bowden PE, Haley JL, Kansky A, Rothnagel JA, Jones DO, Turner RJ. Mutation of a type II keratin gene (K6a) in pachyonychia congenita. Nat Genet 1995; 10 (3): 363-5.

7. Rodrigues RG. Three successive generations of women with anhidrotic/hypohidrotic ectodermal dysplasia. J Natl Med Assoc 2005; 97 (1): 99-101.
8. Kere J, Srivastava AK, Montonen O, Zonana J, Thomas $\mathrm{N}$, Ferguson B, et al: X-linked anhidrotic (hypohidrotic) ectodermal dysplasia is caused by mutation in a novel transmembrane protein. Nat Genet 1996; 13(4): 409-16.

9. Stevenson AC, Kerr CB: On the distribution of frequencies of mutations to genes determining harmful traits in man. Mutat Res 1967; 4: 339-352.

10. Arenas R. Displasia Ectodérmica Anhidrótica. En: Arenas R Editores. Atlas de Dermatología. Diagnóstico y Tratamiento. $3^{\text {a }}$ ed. México D.F: McGraw-Hill Interamericana; 2005. p 258-9.

11. BowdenPE, HaleyJL, KanskyA, RothnagelJA, JonesDO, TurnerRJ. Mutation of a type II keratin gene (K6a) in pachyonychia congenita. Nat Genet 1995; 10 (3): 363-5.

12. Monreal AW, Zonana J, Ferguson B. Identification of a new splice form of the EDA1 gene permits detection of nearly all X-linked hypohidrotic ectodermal dysplasia mutations. Am J Hum Genet 1998; 63 (2): 380-9.

13. Scaling skin in the neonate: a clue to the early diagnosis of X-linked hypohidrotic ectodermal dysplasia (ChristSiemens-Touraine syndrome). The Executive and Scientific Advisory Boards of the National Foundation for Ectodermal Dysplasias, Mascoutah, Illinois. J Pediatr 1989; 114 (4 Pt 1): 600-2.

14. Sybert V. Hypohidrotic ectodermal dysplasia. En: Sybert V, Editores. Genetic skin disorders. New York: Oxford University. Press, 1997: 254-7.

15. KaercherT. Ocular symptoms and signs in patients with ectodermal dysplasia syndromes. Graefes Arch Clin Exp Ophthalmol 2004; 242 (6): 495-500.

16. Hickey AJ, Vergo TJ Jr. Prosthetic treatments for patients with ectodermal dysplasia. J Prosthet Dent 2001; 86(4): 364-8.

17. Imirzalioglu P, Uckan S, Haydar SG. Surgical and prosthodontic treatment alternatives for children and adolescents with ectodermal dysplasia: a clinical report. J Prosthet Dent 2002; 88 (6): 569-72.

18. Dhanrajani PJ, Jiffry AO. Management of ectodermal dysplasia: a literature review. Dent Update 1998; 25 (2): 73-5.

19. Lypka M, Yarmand D, Burstein J, Tso V, Yamashita DD. Dental implant reconstruction in a patient with ectodermal dysplasia using multiple bone grafting techniques. J Oral Maxillofac Surg 2008; 66 (6): 1241-4. 